(1)

Acta Botanica Brasilica - 32(3): 479-486. July-September 2018. doi: 10.1590/0102-33062018abb0241

\title{
Nectar ecology of the endemic epiphytic hummingbird-pollinated bromeliad Vriesea altodaserrae: secretion dynamics and pollinator visitation pattern
}

\section{Carlos E. P. Nunes ${ }^{1}$ (D), Joseildo Briet ${ }^{2}$ (D), Leonardo Galetto ${ }^{3}$, , Marlies Sazima $^{4}$ (1) and Felipe W. Amorim ${ }^{5 *}$ (I)}

Received: July 5, 2018

Accepted: July 24, 2018

\begin{abstract}
Hummingbirds are the main pollinators of most bromeliad species, whose nectar traits usually respond to the selective pressures imposed by pollinators. Considering the specialization of hummingbird-pollinated bromeliads, we expect a close relationship between nectar ecophysiology and the needs of the main pollinators. In this sense, we studied the nectar ecology of the endemic epiphytic bromeliad Vriesea altodaserrae by assessing its nectar traits to address the following questions: i) do flowers respond to successive experimental removals of nectar? ii) is hummingbird visitation frequency related to nectar secretion pattern? We found that $V$. altodaserrae depended completely on hummingbirds for sexual reproduction, and nectar composition was consistent with that of most hummingbirdpollinated species. Most of the nectar was secreted at bud stage and, if not removed, flowers reabsorb it at the end of their lifespan. Total nectar production did not change after successive removals, and nectar secretion rhythm did not affect the frequency of hummingbird visits. Vriesea altodaserrae was visited by two-thirds of the hummingbird species recorded at the study site, but especially by those of Trochilinae subfamily, suggesting specialization for this group of hummingbirds and highlighting the importance this endemic bromeliad as a keystone species in areas of highland Atlantic forest.
\end{abstract}

Keywords: Bromeliaceae, nectar traits, Phaethornithinae, Trochilidae, specialized pollination system, sugar chemical composition

\section{Introduction}

Most bromeliad species rely on animal-pollination for sexual reproduction and nectar is by far the most common reward provided by these plants to pollinators (Bernardello et al. 1991; Schmid et al. 2011), which include butterflies, hawkmoths, bees, bats and non-flying mammals (Kessler \& Krömer 2000; Varassin \& Sazima 2000; Machado \& Semir 2006; Piacentini \& Varassin 2007). Hummingbirds, however, are the major group of pollinators of the majority of bromeliad species (Kessler \& Krömer 2000; Matallana et al. 2010). In such interactions, nectar sugar composition and secretion dynamics may respond to selective pressures imposed by pollinators (Baker \& Baker 1983; SchmidtLebuhn et al. 2007; Amorim et al. 2013). In fact, specialized hummingbird-pollinated species are generally characterized by sucrose-rich or sucrose-dominant nectar composition (Baker \& Baker 1983; Bernardello et al. 1991; Krömer et al. 2008; but see also Hornung-Leoni et al. 2007; 2013).

1 Programa de Pós-Graduação em Biologia Vegetal, Instituto de Biologia, Universidade Estadual de Campinas, 13083-970, Campinas, SP, Brazil

2 Universidade de Taubaté, 12020-270, Taubaté, SP, Brazil

3 Instituto Multidisciplinario de Biología Vegetal, Universidad Nacional de Córdoba, 5000, Córdoba, Argentina

4 Departamento de Biologia Vegetal, Instituto de Biologia, Universidade Estadual de Campinas, 13083-970, Campinas, SP, Brazil

5 Laboratório de Ecologia da Polinização e Interações, Departamento de Botânica, Instituto de Biociências, Universidade Estadual Paulista

“Júlio de Mesquita Filho", 18618-689, Botucatu, SP, Brazil

* Corresponding author: amorimfelipe@yahoo.com.br 
Nectar secretion dynamics and response to experimental successive nectar removals were previously studied in some hummingbird-pollinated bromeliads which presented common patterns (i.e., Galetto \& Bernardello 1992; Ordano \& Ornelas 2004; Stahl et al. 2012). These common patterns of nectar secretion include the absence of nectar secretion before flower opening; continuous secretion during anthesis and, in most species, the absence of nectar resorption at the end of flower lifespan (Galetto \& Bernardello 1992; Ordano \& Ornelas 2004; Stahl et al. 2012). Some studies which assessed nectar traits of tropical bromeliads also have demonstrated a close relationship between nectar secretion patterns and pollinator activity (e.g. Ordano \& Ornelas 2004; Stahl et al. 2012). For example, in the bat-pollinated bromeliad Werauhia gladioliflora, nectar availability is negatively associated with the time spent by bats hovering in each flower (Tschapka \& Helversen 2007). Nevertheless, some hummingbird-pollinated Bromeliaceae show different responses to experimental successive nectar removals. For example, some Tillandsia and Puya species increase total nectar production after successive removals (Galetto \& Bernardello 1992; Ordano \& Ornelas 2004). However, most species do not change total nectar production after experimental removals (Galetto \& Bernardello 1992). On the other hand, nectar replenishment after successive removals seems to be a general trend in animal-pollinated bromeliads (Galetto \& Bernardello 1992; Ordano \& Ornelas 2004; Tschapka \& Helversen 2007; Stahl et al. 2012). Though nectar replenishment may represent costs to plant reproduction in terms of seed production in some cases (see Ordano \& Ornelas 2005).

Bromeliads represent about $30-45 \%$ of the plant species used by hummingbirds as nectar source in the Atlantic forest (Buzato et al. 2000; Vizentin-Bugoni et al. 2014). Despite their importance as one of the main food sources for hummingbirds in this ecosystem, detailed analyses of nectar traits, as well as secretion dynamics and pollinator effect on its total production, have seldom been investigated in hummingbird-pollinated bromeliads in the Atlantic forest (Canela \& Sazima 2003; 2005). Moreover, especially for species of the genus Vriesea, one of the most important genera of bromeliads from the Atlantic forest (Stehman et al. 2009), nectar studies remained focused on its availability (Sazima et al. 1999; Silva \& Piratelli 2014) and sometimes in its sugar chemical composition (Bernardello et al. 1991; Krömer et al. 2008), with no objective of relating such information with the behavior or visitation patterns of pollinators. Therefore, analyzing such ecophysiological traits of plant-pollinator interactions would be useful to understand the underlying processes in the evolution of pollination systems (Galetto \& Bernardello 2004; Amorim et al. 2013; Maruyama et al. 2014).

In this sense, we studied nectar ecology of the epiphytic bromeliad Vriesea altodaserrae, an endemic species of highland Atlantic forests areas of Southeastern Brazil. Considering the high specialization of hummingbird-pollinated bromeliads, we expected a fine tuning between plant traits such as, flower morphology and nectar ecophysiology, and pollinator morphology and behavior. In this work, we assessed (i) plant dependence on pollinators to set fruit; (ii) the morphological match between flower and bills of the main pollinator; (iii) daily amount of reward available for pollinators; (iv) nectar sugar chemical composition and (v) secretion dynamics; and then we addressed the following questions: (vi) do flowers respond to successive experimental removals of nectar? and (vii) is hummingbird visitation frequency related to nectar secretion pattern.

\section{Materials and methods}

\section{Study site and species}

This study was conducted from March to May, between the rainy and the dry seasons, during the years 2009, 2012 and 2014 in a highland Atlantic forest reserve (Montane Ombrophilous Dense Forest) located at Santa Virginia Field Station (SVFS: $23^{\circ} 17^{\prime}-23^{\circ} 24^{\prime} \mathrm{S} 45^{\circ} 03^{\prime}-45^{\circ} 11^{\prime} \mathrm{W}$ ), within the Serra do Mar State Park - SMSP, São Paulo state, Southeastern Brazil. The total area encompassed by the reserve is approximately $17,500 \mathrm{ha}$, and it is situated in the municipalities of São Luiz do Paraitinga, Cunha, and Ubatuba (Veloso et al. 1991). Elevation at the study site varies from 850 to $1,200 \mathrm{~m}$ a.s.l. and climate is Subtropical humid (Cfa or Cfb according to Köppen 1948), with average annual rainfall of 2,300 $\mathrm{mm}$ and more than $60 \mathrm{~mm}$ per month, even during the driest months (Joly et al. 2012).

Vriesea altodaserrae L.B.Sm is an endemic epiphyte that occurs in the highland Atlantic forest at the Serra do Mar mountain range from southeastern to southern Brazil (Buzato et al. 2000; Forzza et al. 2015). In the SVFS, V. altodaserrae occurs in both canopy treetops or in clearings at the forest border where the species can be observed growing close to the soil. This species grows as rosettes, usually forming clumps of two to 10 ramets, being one of the most conspicuous epiphytic species in the study area due to its large size (flowering rosettes with more than $50 \mathrm{~cm}$ diameter and $120 \mathrm{~cm}$ high). Flowering phenology presents a supraannual pattern (sensu Newstrom et al. 1994) with most individuals flowering synchronously within the flowering season every two years (Buzato et al. 2000). At the SVFS, plants were observed blooming from February to May. Mature ramets produce single panicle inflorescences which produce $251 \pm 66$ flowers ( $\mathrm{n}=8$ plants) opening three to seven flowers per day. This species is typically ornithophilous and presents reddish bracts disposed in its central axis contrasted with yellowish tubular flowers (Fig. 1A-E) 35.78 $\pm 3.13 \mathrm{~mm}$ in length ( $\mathrm{n}=15$ flowers in 8 plants) and stigma and anthers located around the entrance of the flower tube, forming a semicircle (Fig. 1D). In order to estimate the 
amount of energy an individual plant produces a day and relate it to the average amount needed by hummingbirds, the number of open flowers per plant was counted on 16 plants, during 22 consecutive days.

\section{Breeding system and pollinators}

We assessed the dependence of $V$. altodaserrae on pollinators to set fruit by isolating flowers with nylon mesh bags. For this purpose, 527 flowers distributed among five plants were isolated and fruit set was assessed after 45 days. Fruit set under natural conditions was also assessed from 1805 flowers distributed in seven plants $(258 \pm 68$ flowers per plant).

Floral visitors and pollinators were determined using focal observations in single rosettes from $7 \mathrm{~h} 00 \mathrm{~min}$ to 20h00min during the blooming season of 2010, 2012 and 2014. Observations were made directly or with aid of video cameras, totalizing $90 \mathrm{~h} 40 \mathrm{~min}$. Flower visitors which contacted anthers and stigma during visitation were considered pollinators. The relative frequency of each pollinator species was calculated by dividing the number of visits of each species by the total number of legitimate visits observed for all pollinator species. To characterize hummingbird foraging activity pattern along the day, we calculated the mean number of visits per plant per day for the periods $07 \mathrm{~h} 00 \mathrm{~min}-10 \mathrm{~h} 00 \mathrm{~min}, 10 \mathrm{~h} 01 \mathrm{~min}-13 \mathrm{~h} 00 \mathrm{~min}$, $13 \mathrm{~h} 00 \mathrm{~min}-16 \mathrm{~h} 00 \mathrm{~min}$ and $16 \mathrm{~h} 00 \mathrm{~min}-19 \mathrm{~h} 00 \mathrm{~min}$. Finally, in order to analyse the morphological match between distinct hummingbird species visiting V. altodaserrae and corolla tube of this plant, we measured the length of the corolla tube of 23 individual plants (one flower per plant) and compared to the measures of bill-plus-tongue taken from Vizentin-Bugoni et al. (2014).
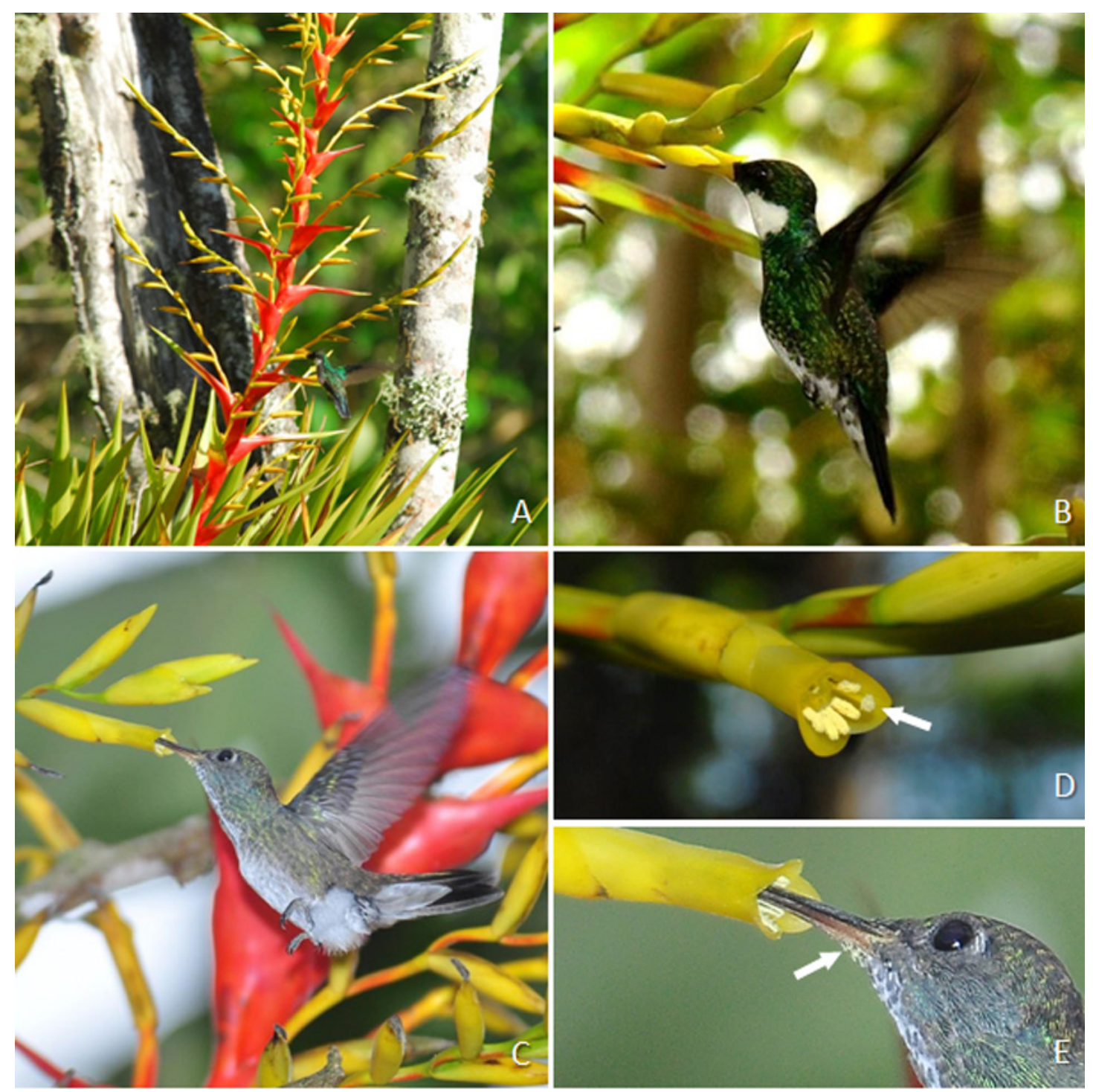

Figure 1. Plant, flowers, and hummingbird pollinators of Vriesea altodaserrae: A. view of plant and inflorescence visited by Leucochloris albicollis; B. Leucochloris albicollis probing for nectar at a flower; C. Female Thalurania glaucopis visiting flower; D. corolla with stigma (arrow) sided by anthers; E. detail of T. glaucopis visiting flower and the local where pollen is deposited on the base of its bill (arrow). 
Nectar: secretion pattern, removal effects, and sugar composition

Nectar secretion dynamics, floral response to repeated nectar removals and sugar composition analyses were performed according to Galetto \& Bernardello (2005) and Amorim et al. (2013). Nectar volume was measured using a microliter graded syringe (Hamilton, NV, USA) and sugar concentration (percentage sucrose, massimass) was measured with a pocket refractometer (0-50\%; Atago, Tokyo, Japan). The amount of sugar in nectar was quantified and expressed in milligrams following Galetto \& Bernardello (2005). Nectar secretion pattern was assessed from 27 flowers distributed in six plants (three to five flowers per plant). Flowers were isolated with nylon mesh bags during the bud stage in the night before the beginning of the experiment. Then, nectar dynamics was analyzed during a $12-\mathrm{h}$ period $(07 \mathrm{~h} 00 \mathrm{~min}$ to 19h00 min) at 3-h intervals, with nectar measures made from flower opening until senescence. In total, the dynamics of nectar throughout anthesis was analyzed in five flower sets of 5-6 flowers each. The nectar was drained and measured once in each flower set, allowing it to accumulate until the next measurement in an untouched new flower set. Each flower set consisted of flowers from different individuals in order to cover inter-plant variations. Then, we calculate the net nectar production rate per hour (NNPR) as the ratio of secreted sugar (in $\mathrm{mg}$ ) in each interval by the number of hours of the secretion period. Net nectar resorption rate (NNRR) was similarly calculated as the ratio of resorbed sugar (in $\mathrm{mg}$ ) by the number of hours of the resorption period (see Galetto \& Bernardello 2004).

In order to evaluate the floral response to a simulated pollinator activity (i.e., multiple visits to the same flowers), we settled an experimental design withdrawing nectar from flowers over the course of anthesis. We compared total accumulated nectar between unvisited (control) and four 'visited' set of flowers (i.e., nectar experimentally drained) with a different number of nectar removals. We carried out nectar removals at 3-h intervals during flower lifespan. A new untouched flower set was included in each subsequent removal session. Thus, in the first set of flowers (set 1 ), the nectar was drained five times, the second (set 2) four times, and so on until set 5 (see details in Galetto \& Bernardello 2004, but also see Amorim et al. 2013). In this last group (set 5, control), nectar was drained only once allowing its accumulation until the end of flower anthesis, marked by the closure of the corolla due to the wilting of petals.

To analyze nectar sugar composition, three nectar samples from three individual plants were collected in the field and stored on Whatman No. 1 chromatography paper. These samples were processed with gas-liquid chromatography (GLC) to determine the types of sugar in nectar and their respective proportions (Galetto \& Bernardello 2005). The sucrosehexose ratio was calculated as sucrose(glucose + fructose), in which values below 0.1 indicate hexose-dominant nectar, values between 0.1 and 0.499 indicate hexose-rich nectar, $\geq 0.5$ indicate sucroserich nectar and $\geq 1.0$ represent sucrose-dominant nectar (according to Baker \& Baker 1983).

To assess the daily total amount of energy offered by $V$. altodaserrae individual plants to hummingbirds, we estimated the total amount of nectar from the minimum and maximum number of flowers produced per plant in a single day with nectar removals simulating hummingbird visits. We also used the minimum and maximum amount of nectar produced per set of flower in the experiment of nectar secretion dynamics to calculate the minimum and maximum of energy provided for pollinators per individual plant. In this sense, the minimum amount of energy available to pollinators by one plant per day was estimated as the minimum number of opened flowers multiplied by the minimum amount of sugar produced in one day. Conversely, the maximum amount of energy available was estimated as the maximum number of opened flowers multiplied by the maximum amount of sugar produced in one day. Then, we converted the minimum and maximum amount of sugar $(\mathrm{mg})$ in their equivalent of energy units $(\mathrm{kJ})$ (see details in Galetto \& Bernardello 2005).

\section{Statistical analysis}

To test the relationship between floral display (total number of flowers per plant) and the fruit set we performed a simple linear regression. In order to characterize the different phases of the nectar dynamics (i.e., active nectar secretion, cessation and resorption periods), we performed a one-way analysis of variance (ANOVA) and used a Tukey post-hoc test for multiple comparisons among pairs of means (Zar 2010). For this analysis, we tested for differences in the nectar volume, concentration, and content of sugar among sets of flowers. We analyzed the effect of successive experimental withdraws of nectar (simulating removals by floral visitors) to the total amount of sugar (solutes in $\mathrm{mg}$ ) produced by each set of flowers accounting for the idiosyncratic variation in nectar production of each plant used in the experiment. For that, we performed a linear mixed model (LMM) using individual plants as a random effect and total amount of sugar produced in each set as fixed effect. Then, to test the significance of our fixed effect, we used the function anova in $\mathrm{R}$ to perform a likelihood ratio test comparing a full model with both fixed and random effects with a null model with only the random effect. For this analysis, we used only the set of flowers before the resorption period (set 1 to set 4 ). Hence, set 5 was not included in the statistical analysis since the effects of successive nectar removal on its total production are mixed with resorption effects (see Amorim et al. 2013).

Finally, in order to test whether the number of hummingbird visits to $V$. altodaserrae flowers is affected by 
nectar secretion dynamics, we used generalized linear mixed models (GLMM with Poisson error distribution) to build models considering the amount of sugar (milligrams) and period of the day as fixed factors, and day of observation as random effect. Then, we used Akaike Information Criterion (AIC) to compare the full model which included both fixed effects (amount of sugars and period of the day) without interaction between them, with models considering each one of the fixed effects alone (amount of sugar or period of the day), and a null model with no fixed effects, which included only the intercept and the random effect (day of observation). To choose the best fit, we considered the lowest values of AIC and $\triangle A I C$ (Burnham \& Anderson 2002). We used the lme4 package in R to perform GLMM (Bates et al. 2015) and bbmle package for model selection analysis (Bolker \& R Core Team 2017). We plotted the dispersal of the residuals against the fitted values in order to validate the models. All analyses were made in $\mathrm{R}$ programming language version 3.4.3 (R Core Team 2017).

\section{Results}

\section{Breeding system and pollinators}

Vriesea altodaserrae does not set fruits from spontaneous self-pollination and completely depends on pollinators for sexual reproduction as none of the bagged flowers resulted in fruit. However, fruit set ranged from $4.7 \%$ to $61.1 \%$ (median $25.2 \%, \mathrm{n}=8$ plants) with no significant relationship between the floral display (total number of flowers per plant) and the number of fruits produced ( $F 1,5$ $=0.84 ; R 2=0.14 ; p=0.4)$ in natural conditions. Trochilidae hummingbirds were the main flower visitors and pollinators, but the flowers were also frequently visited by the Scalethroated Hermit, Phaethornis eurynome (Phaethornithinae). The most frequent species (in descending order) were: the Violet-capped Woodnymph Thalurania glaucopis (Fig. 1C, D), the White-throated hummingbird Leucochloris albicollis (Fig. 1A, B), and the Brazilian Ruby Clytolaema rubricauda. Thalurania glaucopis and L. albicollis accounted together for about $70 \%$ of all recorded visits. While other species like A. versicolor, Florisuga fusca and the hermit hummingbird $P$. eurynome were less frequent flower visitors and can be considered occasional pollinators. Total number of visits and relative frequencies of each pollinator species are presented in Table 1.

While feeding on nectar, all hummingbird species contacted both stigma and anthers with their bills. Pollen grains were also deposited on the feathers at the base of the bill of Trochilinae hummingbirds (Fig. 1E), and only on the bill of the hermit P. eurynome (see Video S1 in supplementary material). All hummingbird species presented bill-plustongue lengths significantly shorter than the corolla tube length $(3.4 \pm 0.5 \mathrm{~cm})$ with an exception for $P$. eurynome (see Tab. 1).
Table 1. Bill plus tongue length (from Vizentin-Bugoni et al. 2014) and relative frequencies of the pollinators of Vriesea altodaserrae after $90 \mathrm{~h} 40 \mathrm{~min}$ of focal observations during the flowering seasons of 2010, 2012 and 2014 at Santa Virgínia Field Station, Serra do Mar State Park, São Paulo, Brazil. * indicate significantly higher value of bill-plus-tongue length in comparison to corolla tube length $(t=7.59, p<0.0001)$.

\begin{tabular}{|c|c|c|c|}
\hline Species & N of visits & $\begin{array}{c}\text { Relative } \\
\text { frequency } \%\end{array}$ & $\begin{array}{c}\text { Bill + tongue } \\
\text { length }(\mathrm{cm})\end{array}$ \\
\hline Thalurania glaucopis & 50 & 36 & $2.4 \pm 0.1$ \\
\hline $\begin{array}{c}\text { Leucochloris albicollis } \\
\text { Clytolaema rubricauda }\end{array}$ & 49 & 35.3 & $2.7 \pm 0.1$ \\
\hline Phaethornis eurynome* & 8 & 15.1 & 2.5 \\
\hline Florisuga fusca & 8 & 5.8 & $4.5 \pm 0.1^{*}$ \\
\hline Amazilia versicolor & 2 & 5.8 & $2.9 \pm 0.1$ \\
\hline
\end{tabular}

Nectar: sugar composition, secretion pattern, removal effects and relation to pollinators visits

Nectar was composed of $57.8 \pm 2.1 \%$ of sucrose, $20.1 \pm$ $1.5 \%$ of glucose and $22.1 \pm 0.7 \%$ of fructose. The sucrose/ hexose ratio was $1.4 \pm 0.1$ and the hexose ratio was $0.9 \pm$ 0.04 , characterizing sucrose-dominant nectar (sucrose/ hexose ratio 21.0 ) with an equilibrated proportion of glucose and fructose (hexose ratio around 1.0).

The number of open flowers per individual per day ranged from one to six, or an average of $3.4 \pm 1.1$ flowers opened per plant each day ( $\mathrm{n}=91$ plants). Thereby, our estimation of the daily amount of sugar available per plant ranged from 12.2 to $291.1 \mathrm{mg}$. Hence, the amount of energy offered by $V$. altodaserrae plants to hummingbirds in a daily base ranges from 0.2 to $4.9 \mathrm{~kJ}$. Nectar secretion, in turn, started before the sunrise during the pre-anthesis. Newly opened flowers contained $36.2 \pm 13.7 \mu \mathrm{l}$, with $26.5 \pm 2.8 \%$ (mass/mass in sucrose equivalents) of sugar concentration and $10.3 \pm 3.5 \mathrm{mg}$ of solutes (Tab. 2, Fig. 2). After a higher initial nectar secretion during the pre-anthesis, flowers present a small NNPR (1.0 mg.h-1) along the day (Tab. 2, Fig. 2). Then, just before the sundown, from $1600 \mathrm{~h}$ to $1900 \mathrm{~h}$ we observed a significant decrease in the amount of nectar solutes in terms of $\mathrm{mg}$ of sugars $(F 4,21=12.512 ; P<0.00002)$ and also concentration $(F 4,21=2.84 ; P<0.05)$. This period is characterized by active nectar resorption, in which nectar sugar is recovered by the flowers with a NNRR of 4.15 $\mathrm{mg} \cdot \mathrm{h}^{-1}$. During this stage, there was a constant decrease in nectar volume and amount of solutes (Tab. 2, Fig. 2) in unvisited (i.e. bagged) flowers, which began to wilt. Flowers did not respond to nectar successive removals. When nectar production was compared among flower sets (excluding the last period under active nectar resorption), the effect of experimentally successive removals on the total amount of sugar produced was not significant $\left(\chi^{2}=2.53\right.$, d.f. $=3$, $P=0.470)$. Nevertheless, nectar was replenished after experimental removals. 


\section{Carlos E. P. Nunes, Joseildo Briet, Leonardo Galetto, Marlies Sazima and Felipe W. Amorim}

Table 2. Nectar removal effects on total nectar production of Vriesea altodaserrae flowers in a montane ombrophilous dense forest at Núcleo Santa Virgínia, Serra do Mar State Park - SP. Data represent mean \pm SD of volume ( $\mu$ l), concentration (\% massimass) and mass of sugars ( $m$ g of nectar sugar produced per flower, $n=5$ flowers per set of flowers sampled at each time). Equal letters in lines represent non-significant differences among sets $(P>0,05)$.

\begin{tabular}{|c|c|c|c|c|c|c|}
\hline \multirow{2}{*}{ Set of flowers } & \multicolumn{5}{|c|}{ Sampling time (h) } & \multirow{2}{*}{ Total amount produced } \\
\hline & $7: 00$ & $10: 00$ & $13: 00$ & $16: 00$ & $19: 00$ & \\
\hline \multicolumn{7}{|l|}{1} \\
\hline $\begin{array}{l}\mathrm{mg} \\
\mu \mathrm{l} \\
\%\end{array}$ & $\begin{array}{c}10.30 \pm 3.49 \\
36.17 \pm 13.70 \\
26.50 \pm 2.79\end{array}$ & $\begin{array}{c}8.67 \pm 5.49 \\
37.33 \pm 20.95 \\
22.50 \pm 5.68\end{array}$ & $\begin{array}{c}1.62 \pm 1.73 \\
7.50 \pm 6.66 \\
19.33 \pm 4.26\end{array}$ & $\begin{array}{c}2.03 \pm 1.78 \\
14.42 \pm 11.52 \\
14.17 \pm 2.56\end{array}$ & $\begin{array}{l}0.32 \pm 0.32 \\
4.33 \pm 3.72 \\
6.95 \pm 3.43\end{array}$ & $\begin{array}{c}22.94 \pm 10.37 \\
99.75 \pm 45.87 \\
a\end{array}$ \\
\hline \multicolumn{7}{|l|}{2} \\
\hline $\begin{array}{l}\mathrm{mg} \\
\mu \mathrm{l} \\
\%\end{array}$ & & $\begin{array}{c}15.66 \pm 6.98 \\
53.20 \pm 22.21 \\
26.60 \pm 3.96\end{array}$ & $\begin{array}{c}10.23 \pm 10.65 \\
45.80 \pm 40.33 \\
18.40 \pm 3.73\end{array}$ & $\begin{array}{c}2.66 \pm 1.24 \\
16.80 \pm 6.69 \\
15.40 \pm 5.03\end{array}$ & $\begin{array}{c}0.84 \pm 0.71 \\
6.60 \pm 3.44 \\
11.00 \pm 3.70\end{array}$ & $\begin{array}{c}29.40 \pm 16.65 \\
122.40 \pm 57.26 \\
a\end{array}$ \\
\hline \multicolumn{7}{|l|}{3} \\
\hline $\begin{array}{l}\mathrm{mg} \\
\mu \mathrm{l} \\
\%\end{array}$ & & & $\begin{array}{c}17.73 \pm 11.96 \\
70.20 \pm 46.45 \\
23.20 \pm 1.10\end{array}$ & $\begin{array}{c}3.85 \pm 4.47 \\
22.40 \pm 15.92 \\
12.94 \pm 7.04\end{array}$ & $\begin{array}{c}2.28 \pm 1.53 \\
18.80 \pm 7.60 \\
12.10 \pm 6.77\end{array}$ & $\begin{array}{c}23.86 \pm 13.98 \\
111.40 \pm 51.90 \\
a\end{array}$ \\
\hline \multicolumn{7}{|l|}{4} \\
\hline $\begin{array}{l}\mathrm{mg} \\
\mu \mathrm{l} \\
\%\end{array}$ & & & & $\begin{array}{c}19.31 \pm 6.50 \\
74.00 \pm 24.08 \\
23.96 \pm 1.48\end{array}$ & $\begin{array}{c}2.98 \pm 2.99 \\
18.60 \pm 16.77 \\
13.44 \pm 3.70\end{array}$ & $\begin{array}{c}22.29 \pm 7.3 \\
92.60 \pm 29.59 \\
a\end{array}$ \\
\hline
\end{tabular}
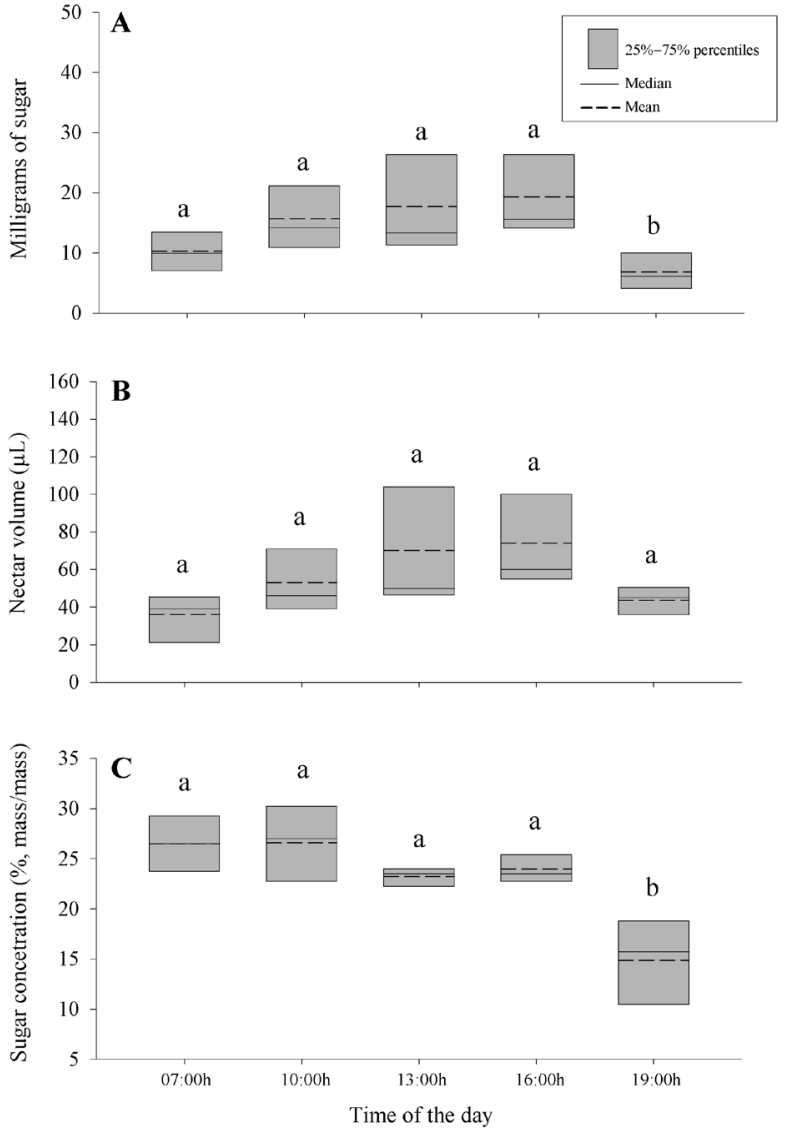

Figure 2. Nectar natural secretion dynamics (bagged flowers) of Vriesea altodaserrae along the flower anthesis period (from 07h00min to $19 \mathrm{~h} 00 \mathrm{~min}$ ) showing: A. Sugar content (mg), B. volume $(\mu \mathrm{l})$ and $\mathbf{C}$. concentration (\% of mass/mass in sucrose equivalents). For each variable, boxes accompanied by the same letters did not differ in the post-hoc Tukey test $(\mathrm{CI}=95 \%)$.
Pollinator's visits were concentrated in the morning and at the beginning of the afternoon, from 10h00min to $13 \mathrm{~h} 00 \mathrm{~min}$ (Fig. 3). The amount of nectar available to pollinators had no effect on the number of hummingbird visits since the model considering only the period of day performed better $(\mathrm{AIC}=127.8 ; \triangle \mathrm{AIC}=0.0$; d.f. $=5)$ than the full (AIC = 131.5; $\triangle \mathrm{AIC}=3.7$; d.f. $=6$ ) and the null (AIC $=172.2 ; \triangle \mathrm{AIC}=44.4$; d.f. $=2$ ) models, as well as than the model considering only the amount of sugar as fixed factor $(\mathrm{AIC}=172.1 ; \triangle \mathrm{AIC}=44.3$, d.f. $=3)$.

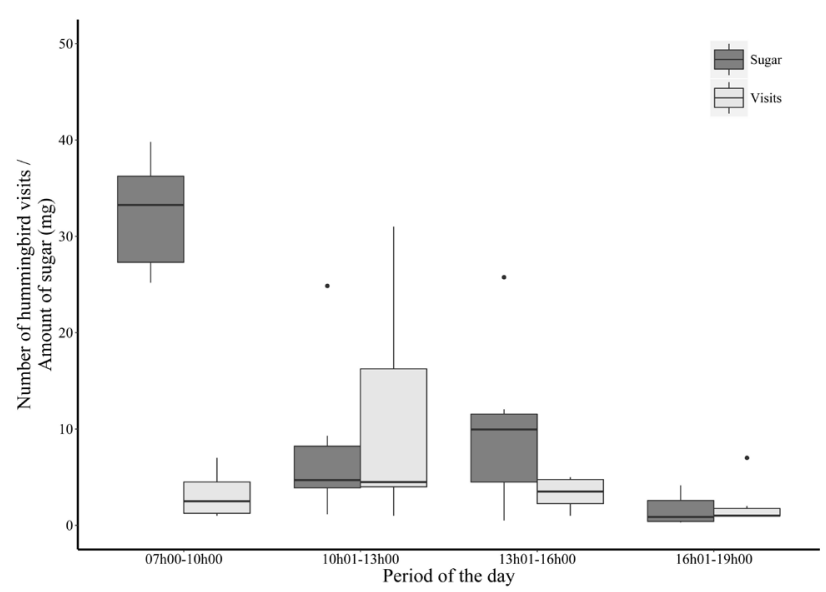

Figure 3. Nectar production and pollinator visits of Vriesea altodaserrae. Number of pollinator visits per plant and amount of nectar sugar content produced per plant after successive removals along the day (with exception of the first group, which corresponds to recent open flowers without previous removal). Medians, 25 $\%$ and $75 \%$ percentiles. Dots represent outliers. 


\section{Discussion}

Vriesea altodaserrae is an endemic species that depends strictly on hummingbirds for sexual reproduction and exhibits a higher dependence in three out of the six species recorded visiting its flowers (Vizentin-Bugoni et al. 2014). The high frequency of hummingbird visits to V. altodaserrae flowers clearly reveals that fruit set is not limited by pollinator activity. However, the high variation in fruit set ( $5 \%$ to $60 \%$ ) suggests that the species heavily depends on pollen flow among plants mediated by hummingbirds to set fruit (see Sutherland 1986). Once the energy needs of hummingbirds in the natural habitat may range from 29.1 to $81.7 \mathrm{~kJ}$ day $^{-1}$ (Weathers et al. 1989; Powers \& Conley 1994), even the maximum estimated value produced by one plant of $V$. altodaserrae is not enough to supply all the needs of a single hummingbird. This fact promotes visitation of more than one plant in a population by birds to fulfill their daily energy requirements, enhancing crossing among individual plants or visitation of different plant species in the community.

Different traits reported for other hummingbirdpollinated bromeliads as continuous secretion during flower lifetime, nectar replenishment after removals, a medium sugar concentration (10-30\%) and the sucrose-dominant composition were also observed for this endemic species (Galetto \& Bernardello 1992; Ordano \& Ornelas 2004; Krömer et al. 2008; Stahl et al. 2012). Nevertheless, other characteristics linked to nectar secretion dynamics did not match with previous findings. For example, V. altodaserrae secretes nectar before flower opening and reabsorb nectar at the end of flower lifetime as observed only in Abromeitiella lorentziana (Galetto \& Bernardello 1992). These complex variations indicate that it is necessary to perform detailed studies on nectar ecophysiology in more species, as well as on pollinator behavior, in order to better understand bromeliadhummingbird interactions and their consequences for plant reproduction.

Our study also demonstrates that total nectar production in $V$. altodaserrae is not affected by pollinator visits to flowers simulated by experimental nectar draining, since nectar is replenished according to a relatively fixed nectar secretion pattern. This finding in $V$. altodaserrae match with most hummingbird-pollinated Bromeliaceae species previously studied, with the exception of three species (two Tillandsia and Puya spathaceae) that showed total nectar secretion increased after successive removals (Galetto \& Bernardello 1992; Ordano \& Ornelas 2004). The amount of sugar accumulated along the day was not related to the frequency of hummingbird visitation to $V$. altodaserrae flowers. The frequency of hummingbird visitation is better explained by the period of the day, revealing that abiotic factors or processes acting at the community level (e.g. Vizentin-Bugoni et al. 2014; Maruyama et al. 2014) are more important for pollinator activity than the mass blooming of a single specialized plant species, such as V. altodaserrae.
Notwithstanding, by showing a nectar secretion pattern different from other bromeliads previously studied, our results reveal that the diversity of ecophysiological patterns for the family Bromeliaceae is wider than was formerly known.

Natural selection mediated by pollinators, however, may have shaped several other flower traits besides nectar composition and secretion patterns. The corolla length of $V$. altodaserrae, for instance, obliges most hummingbirds to insert the entire bill into the corolla tube, and consequently to contact anthers and stigma with the feathers located at the base of the bill. Pollen-carrying on feathers have proved to be more effective for pollination than on bill surface in another Vriesea species with similar floral morphology (Rocca \& Sazima 2013). Hence, short-billed Trochilinae hummingbirds can be regarded as better pollinators of $V$. altodaserrae than the long-billed Phaethornitinae hummingbird, Phaethornis eurynome, which represents the most abundant hummingbird in the area, but one of the less frequent visitors of this plant species. On the other hand, the short-billed Trochilinae hummingbird, Thalurania glaucopis, showed a temporal constancy as the most frequent visitor of V. altodaserrae throughout 2010-2014 (see VizentinBugoni et al. 2014).

It is also interesting that two of the less frequent hummingbird species in the community, Leucochloris albicollis and Amazilia versicolor (see supplementary data in Vizentin-Bugoni et al. 2014) are among the most common visitors of V. altodaserrae. Even Florisuga fusca, one of the rarest hummingbird species recorded previously in the study site, displayed a higher frequency in $V$. altodaserrae flowers than it does in the overall assemblage. Thus, our findings suggest a specialization of $V$. altodaserrae in Trochilinae hummingbirds, similar to what was observed in $V$. rodigasiana in another Atlantic forest site in southeastern Brazil (Rocca \& Sazima 2013). Although V. altodaserrae is not among the most abundant hummingbird-pollinated plants recorded at SVFS (33th of 44 species), this plant interacts with six of the nine hummingbird species recorded in the area (see supplementary data in Vizentin-Bugoni et al. 2014). Hence, our findings highlight the importance of this endemic epiphytic bromeliad as a keystone species in this highland Atlantic forest area.

\section{Acknowledgements}

We thank all the people of the Santa Virgínia Field Station for the facilities and help during fieldwork, J.Vizentin-Bugoni and P.K. Maruyama for their helpful comments on an earlier version of the manuscript. This research was supported by FAPESP as part of the Thematic Project Functional Gradient (03/12595-7), and FWA Ph.D. studies (2007/58666-3); also CNPq (Grant 303084/2011-1 to MS and 148221/2012-2 to CEPN); LG was supported by CONICET, FONCyTand Secretaría de Ciencia y Tecnología de la Universidad Nacional de Córdoba. 


\section{Carlos E. P. Nunes, Joseildo Briet, Leonardo Galetto, Marlies Sazima and Felipe W. Amorim}

\section{References}

Amorim FW, Galetto L, Sazima M. 2013. Beyond the pollination syndrome: nectar ecology and the role of diurnal and nocturnal pollinators in the reproductive success of Inga sessilis (Fabaceae). Plant Biology 15: 317-327.

Baker HG, Baker I. 1983. Floral nectar sugar constituents in relation to pollinator type. In: Jones CE, Little RJ (eds.) Handbook of experimental pollination biology. New York, Van Nostrand Reinhold Co. p. 117-141.

Bates D, Maechler M, Bolker B, Walker S. 2015. Fitting linear mixed-effects modelsusing lme4. Journal of Statistical Software 67: 1-48.

Bernardello G, Galetto L, Juliani HR. 1991. Floral nectar, nectary structure and pollinators in some Argentinean Bromeliaceae. Annals of Botany 67: 401-411.

Bolker B, R Development Core Team. 2017. bbmle: Tools for general maximum likelihood estimation. Vienna, R package version 1.0.20.

Burnham KP, Anderson DR. 2002. Model selection and multimodel inference: a practical information-theoretic approach. New York, Springer-Verlag.

Buzato S, Sazima M, Sazima I. 2000. Hummingbird-pollinated floras at three atlantic forest sites. Biotropica 32: 824-841.

Canela MBF, Sazima M. 2003. Aechmea pectinata: a hummingbird-dependent bromeliad with inconspicuous flowers from the rainforest in southeastern Brazil. Annals of Botany 92: 731-737.

Canela MBF, Sazima M. 2005. The pollination of Bromelia antiacantha (Bromeliaceae) in Southeastern Brazil: Ornithophilous versus melittophilous features. Plant Biology 7: 411-416.

Forzza RC, Costa A, Siqueira Filho JA, et al. 2015. Bromeliaceae. In: Lista de espécies da flora do Brasil. Jardim Botânico do Rio de Janeiro. http:// floradobrasil.jbrj.gov.br/jabot/floradobrasil/FB6417

Galetto L, Bernardello L. 1992. Nectar secretion pattern and removal effects in six Argentinean Pitcairnioideae (Bromeliaceae). Plant Biology 105: 292-299.

Galetto L, Bernardello G. 2004. Floral nectaries, nectar production dynamics and chemical composition in six Ipomoea species (Convolvulaceae) in relation to pollinators. Annals of Botany 94: 269-80.

Galetto L, Bernardello G. 2005. Nectar. In: Dafni A, Kevan PG, Husband BC. (eds.) Pollination ecology: a practical approach. Cambridge, Enviroquest Ltd. p. 156-512.

Hornung-Leoni CT, González-Gómez PL, Troncoso AJ. 2013. Morphology, nectar characteristics and avian pollinators in five Andean Puya species (Bromeliaceae). Acta Oecologica 51: 54-61.

Hornung-Leoni CT, Sosa V, López MG. 2007. Xylose in the nectar of Puya raimondii (Bromeliaceae), the Queen of the Puna. Biochemical and Systematic Ecology 35: 554-556.

Joly CA, Assis MA, Bernacci LC, Tamashiro JY, Campos MCR, Gomes JAMA. 2012. Floristic and phytosociology in permanent plots of the Atlantic Rainforest along an altitudinal gradient in southeastern Brazil. Biota Neotropica 12: 123-145.

Kessler M, Krömer T. 2000. Patterns and ecological correlates of pollination modes among Bromeliad communities of Andean forests in Bolivia. Plant Biology 2: 659-669.

Köppen W. 1948. Climatología. Ciudad de Mexico, Fondo de Cultura Económica de Mexico.

Krömer T, Kessler M, Lohaus G, Schmidt-Lebuhn NA. 2008. Nectar sugar composition and concentration in relation to pollination syndromes in Bromeliaceae. Plant Biology 10: 502-511.

Machado CG, Semir J. 2006. Fenologia da floração e biologia floral de bromeliáceas ornitófilas de uma área da Mata Atlântica do Sudeste brasileiro. Revista Brasileira de Botânica 1: 163-174.

Maruyama PK, Vizentin-Bugoni J, Oliveira GM, Dalsgaard B. 2014. Morphological and spatio-temporal mismatches shape a neotropical savanna plant-hummingbird network. Biotropica 46: 740-747.
Matallana G, Godinho MAS, Guilherme FAG, Belisario M, Coser TS, Wendt T. 2010. Breeding systems of Bromeliaceae species: Evolution of selfing in the context of sympatric occurrence. Plant Systematics and Evolution 289: 57-65.

Newstrom LE, Frankie GW, Baker HG. 1994. A new classification for plant phenology based on flowering patterns in lowland tropical rain forest trees. Biotropica 26: 141-159.

Ordano M, Ornelas JF. 2004. Generous-like flowers: nectar production in two epiphytic bromeliads and a meta-analysis of removal effects. Oecologia 140: 495-505.

Ordano M, Ornelas JF. 2005. The cost of nectar replenishment in two epiphytic bromeliads. Journal of Tropical Ecology 21: 541-547.

Piacentini VQ, Varassin IG. 2007. Interaction network and the relationships between bromeliads and hummingbirds in an area of secondary Atlantic rain forest in southern Brazil. Journal of Tropical Ecology 23: 663-671.

Powers DR, Conley TM. 1994. Field metabolic rate and food consumption of two sympatric hummingbird species in Southeastern Arizona. Condor 96: 141-150.

R Development Core Team. 2017. R: A language and environment for statistical computing. Vienna, R Foundation for Statistical Computing. https://www.R-project.org/. 28 Feb. 2018.

Rocca MA, Sazima M. 2013. Quantity versus quality: identifying the most effective pollinators of the hummingbird-pollinated Vriesea rodigasiana (Bromeliaceae). Plant Systematics and Evolution 299: 97-105.

Sazima M, Buzato S, Sazima I. 1999. Bat-pollinated flower assemblages and bat visitors at two Atlantic Forest sites in Brazil. Annals of Botany 83: 705-712.

Schmid S, Kamke R, Zillikens A, Steiner J. 2011. Flower visitors of Aechmea nudicaulis (Bromeliaceae): species richness, visitation frequency, and interactions in different habitats of southern Brazil. Studies on Neotropical Fauna and Environment 46: 101-120.

Schmidt-Lebuhn AN, Schwerdtfeger M, Kessler M, Lohaus G. 2007. Phylogenetic constraints vs. ecology in the nectar composition of Acanthaceae. Flora 202: 62-69.

Silva B, Piratelli A. 2014. Foraging behaviour of the scale-throated hermit Phaethornis eurynome Lesson, 1832 (Aves, Trochilidae) in Vriesea incurvata Gaudich (Bromeliaceae). Brazilian Journal of Biology 74: 311-314

Stahl JM, Nepi M, Galetto L, Guimarães E, Machado SR. 2012. Functional aspects of floral nectar secretion of Ananas ananassoides, an ornithophilous bromeliad from the Brazilian savanna. Annals of Botany 109: 1243-52.

Stehman JR, Forzza RC, Salino A, Sobral M, Costa DP, Kamino LHY. 2009 Plantas da Floresta Atlântica, 1st. edn. Rio de Janeiro, Instituto de Pesquisas Jardim Botânico do Rio de Janeiro.

Sutherland S. 1986. Patterns of fruit-set: what controls fruit-flower ratios in plants? Evolution 40: 117-128.

Tschapka M, Helversen O. 2007. Phenology, nectar production and visitation behaviour of bats on the flowers of the bromeliad Werauhia gladioliflora in a Costa Rican lowland rain forest. Journal of Tropical Ecology 23: 385-395.

Varassin IG, Sazima M. 2000. Recursos de Bromeliaceae utilizados por beija-flores e borboletas em Mata Atlântica no Sudeste do Brasil. Boletim do Museu de Biologia Mello Leitão 11: 57-70.

Veloso HP, Rangel-Filho ALR, Lima JCA. 1991. Classificação da vegetação brasileira adaptada a um sistema universal. Rio de Janeiro, Fundação Instituto Brasileiro de Geografia e Estatística - IBGE.

Vizentin-Bugoni J, Maruyama PK, Sazima M. 2014. Processes entangling interactions in communities: forbidden links are more important than abundance in a hummingbird-plant network. Proceedings of the Royal Society B: Biological Sciences 281: 2397-2397.

Weathers W, Stiles FG, Rica DC. 1989. Energetics and water balance in free-living tropical hummingbirds. Condor 91: 324-331.

Zar JH. 2010. Biostatistical analysis. 5th. edn. New Jersey, Prentice Hall. 